\title{
Role Of Pet/Ct Scan In The Assessment Of Primary And Loco Regional Recurrent Breast Cancer
}

\author{
Maha Mourad El-Saeed, Ahmed Mohamed Basiouny, Yasser Ibrahim Abd ElKhalek
}

Radiology Department, Faculty of Medicine, Ain Shams University, Cairo, Egypt

Corresponding author: Maha Mourad El-Saeed, Mobile: +01221967699, E-mail: mahamourad00@ gmail.com

\begin{abstract}
Objective: Study the accuracy of 18F-fluoro-2-deoxy-D-glucose (18F-FDG) positron emission tomography/computed tomography (PET/CT) scan in diagnosis of primary and loco regional recurrent breast masses compared with histopathological results and to correlate the results of 18F-fluoro-2-deoxy-Dglucose (18F-FDG) positron emission tomography/computed tomography (PET/CT) with histopathological findings in breast carcinoma patients.

Methodology: This study is a prospective study conducted on 24 female patients presented to Ain Shams University Hospitals (oncology,surgery and obstetrics and gynecology departments) with pathologically proven breast cancer underwent PET/CT.

Result: SUVmax of the tumor is directly related to the histopathological grade and to the size of the tumor. Invasive ductal carcinoma has predominantly higher SUVmax than invasive lobular carcinomas. Also SUVmax tumor/ SUVaverage liver is more accurate that SUVmax tumor alone. However, no relation between SUVmax and the presence of distant metastasis. 18F-FDG uptake may serve as a prognostic indicator for biological behavior in breast tumors
\end{abstract}

Keywords: Breast cancer, 18F-fluorodeoxyglucose, positron emission tomography/ computed tomography, Simple Uptake Value (SUV), prognostic factors.

\section{INTRODUCTION}

Breast cancer is the most common type of cancer and the second leading cause of cancerrelated death among women. It affects more than 1 million women worldwide. The number of cases worldwide has significantly increased which is attributed to modern lifestyle ${ }^{(\mathbf{1})}$.

Outcomes for breast cancer vary depending on the cancer type, extent of disease, and patient's age. However it is still with poorer prognosis in developing countries when compared to developed countries, Of course its diagnosis plays a role in improving the survival rate of patients. Approximately $30 \%$ of patients relapses within 15 years after initial treatment ${ }^{(2)}$.

Early diagnosis and accurate follow-up of these patients are important for efficient patient management. In addition; early diagnosis of recurrent breast cancer is important for planning future therapeutic strategies which, if initiated without delay, aim either to cure or to prolong disease-free survival and to improve the quality of life of patients with cancer ${ }^{(3)}$.

Standard imaging techniques include radiological examinations, such as $\mathrm{X}$-ray mammography, ultrasonography (US), computed tomography (CT) and magnetic resonance imaging (MRI). Nuclear medicine techniques are also playing an increasing role in diagnosing and staging breast cancer. In the past only bone scintigraphy was used for follow-up of women with breast cancer to detect bone metastases at an early stage.
Other non-radiographic methods included clinical and physical examination, Laboratory investigation of tumor markers and confirmatory pathological examination ${ }^{(4)}$.

Several studies and systematic reviews were carried out to evaluate and compare the accuracy of the different radiographic methods in detection of primary and recurrent breast cancer.

In $1990, \mathrm{~s} ;{ }^{18}$ F-fluoro-2-deoxy-d-glucose positron emission tomography (FDG PET) was introduced in clinical oncology. It has been shown to be an effective and accurate imaging technique for a variety of diagnostic oncology tasks in breast cancer, lymph node staging, staging and restaging of recurrent and metastatic disease, and treatment monitoring ${ }^{(5)}$. FDG PET is an effective whole-body imaging technique, its diagnostic value is based on the detection of metabolic changes preceding structural findings. However, FDG PET is of limited value in the characterization of primary breast lesions owing to its moderate sensitivity compared to that of MRI. On the other hand, the number of involved lymph nodes and the presence, or absence of micro metastatic disease was claimed to be not sufficiently determined with FDG PET alone ${ }^{(\text {(). }}$.

A new promising modality for the early yet accurate detection of relapsing cancer breast is the PET/CT scan. CT, is considered the primary method of investigation because of its low cost and widespread availability, provides high-resolution anatomic details but may underestimate the actual tumor burden by overlooking small tumor clusters in areas of distorted 
anatomy after treatment. ${ }^{18} \mathrm{~F}$-FDG PET/CT provides fused images that demonstrate the complementary roles of functional and anatomic assessments in the diagnosis of cancer recurrence through the precise localization of suspected ${ }^{18}$ F-FDG foci and their characterization as malignant or benign ${ }^{(3)}$.

Some studies have underestimated PET/CT techniques role and accuracy in diagnosing primary or recurrent breast malignancy when compared with other conventional modalities including sonomammography and MRI ${ }^{(7)}$.

This controversial evaluation of PET/CT requires further and continuous studies of the efficiency of this technique and its role as routine method for diagnosis of primary and recurrent breast cancer.

\section{AIM OF THE WORK}

Our aim is to study the accuracy of ${ }^{18} \mathrm{~F}$ fluoro-2-deoxy-D-glucose $\left({ }^{18} \mathrm{~F}-\mathrm{FDG}\right)$ positron emission tomography/computed tomography (PET/CT) scan in diagnosis of primary and loco regional recurrent breast masses compared with histopathological results and to correlate the results of ${ }^{18}$ F-fluoro-2-deoxy-D-glucose $\left({ }^{18} \mathrm{~F}\right.$-FDG) positron emission tomography/computed tomography (PET/CT) with histopthological findings in breast carcinoma patients.

\section{PATIENTS AND METHODS}

This study is a prospective study conducted in Ain Shams University Hospitals (oncology, surgery and obstetrics /gynaecology departments).

The study included 20 female patients who were diagnosed with primary or loco-regionally recurrent breast cancer and were presented to the hospital from June 2017 till June 2018. The study was approved by the Ethics Board of Ain Shams University.

These patients should have fulfilled the following inclusion criteria which mainly were: (1) Female patient above 18 years, (2)Available data concerning breast cancer histological type.

The Exclusion Criteria for this study included (Bitencourt et al,2014): Pregnancy and lactation. Patients with other possible malignant diseases or double primary tumors. Patients who underwent biopsy or surgical intervention in an interval less than 1 month prior to the study. Patients who received chemotherapy 2 weeks prior to the study. Patients who received radiotherapy 3 months prior to the study. Patients with elevated serum creatinine.

Special sheet was taken for each patient to collect the following data: Personal history: name, age, occupation, marital and obstetrical history. Complaint. Results of clinical examination (General and local). Laboratory investigations. Histopathological examination results.

Data were collected after having patients' written informed consent following rules of ethical committee.

All patients underwent PET/CT at our department and the results were correlated with tumor histological type and grade which were collected from the patients for medical documentation and are archived at our department.

\section{${ }^{18}$ F-FDG PET/CT imaging}

All patients underwent ${ }^{18}$ F-FDG PET/CT examinations using a dedicated PET/CT scanner with 50-slice CT (Discovery IQ, optima CT540, GE health care). The patients were asked to fast from all types of food and drinks except water for a minimum of 4-6 hours prior to the examination. Serum glucose levels were measured to ensure euglycemia (Fasting blood glucose level $<200 \mathrm{mg} / \mathrm{dl}$ ). Patients are also advised to have complete rest for 24 hours prior to the examination. For diabetic patients, they were advised to have their breakfast and take their hypoglycemic medications for at least 6 hours before the examination. Approximately 8 $\mathrm{mCi} / 10 \mathrm{~kg}$ of ${ }^{18} \mathrm{~F}-\mathrm{FDG}$ were then injected intravenously with saline infusion. Following $60 \mathrm{~min}$ of bed rest after the injection, the PET scans were obtained. Patients were asked to empty their urinary bladder before the study. Seven to eight bed positions were acquired, with an acquisition time of 2-3 min each. All patients were in a supine -feet first position during the PET/CT scanning. Contrast CT scanning was initiated at the orbitomeatal line and progressed to the mid-thigh (28-30 $\mathrm{mAs} ; 120 \mathrm{kV}$; slice thickness $5 \mathrm{~mm}$ ); the corresponding PET imaging immediately followed over the same body region. The CT data were used for attenuation correction, and the images were reconstructed. Delayed PET CT images were needed in some cases if the uptake of the lesion was controversial.

\section{Imaging interpretation}

The ${ }^{18}$ F-FDG PET/CT imaging data were interpreted by at least two nuclear medicine physicians. All PET/CT images were reviewed at a workstation with fusion software (GE healthcare), which provided 
multiplanar reformatted images and displayed PET images, CT images, and PET/CT fusion images. A nuclear medicine physician reviewed the PET/CT images, and the interpretation was visually performed. For semi-quantitative analysis, $\mathrm{SUV}_{\max }$ of ${ }^{18} \mathrm{~F}-\mathrm{FDG}$ was measured by visually placing the regions of interest (ROIs) around the primary cancer mass that had avid ${ }^{18}$ F-FDG uptake. For compensation of two different PET/CT scanner types, the mean liver SUV values were obtained for all patients. The tumor/liver SUV ratio was calculated and compared using the different PET/CT scanner types. The SUV value was calculated for each patient according to her lean body index.

\section{RESULTS}

The study included 24 female patients with primary or loco regionally recurrent breast cancer presented to Ain Shams University hospitals, at radiology, oncology, surgery and obstetrics and gynecology departments; from June 2017 till June 2018.

Their clinical data are represented in Table (1).

Table (1): Descriptive clinical data of the patients under the study $(\mathrm{n}=24)$.

\begin{tabular}{|l|l|c|}
\hline \multicolumn{2}{|c|}{ Clinical data } & No.=24 \\
\hline \multirow{2}{*}{ Age in years } & Mean \pm SD & $47.25 \pm 12.39$ \\
& Range & $29-69$ \\
\hline \multicolumn{2}{|l|}{ Previous treatment } \\
\hline \multirow{2}{*}{ Surgical treatment } & Negative & $17(70.8 \%)$ \\
& Positive & $7(29.2 \%)$ \\
\hline \multirow{2}{*}{ Chemotherapy } & Negative & $15(62.5 \%)$ \\
& Positive & $9(37.5 \%)$ \\
\hline \multirow{2}{*}{ Radiotherapy } & Negative & $19(79.2 \%)$ \\
& Positive & $5(20.8 \%)$ \\
\hline \multirow{2}{*}{ Bilaterality } & Negative & $20(83.3 \%)$ \\
& Positive & $4(16.7 \%)$ \\
\hline \multirow{2}{*}{ Distant metastasis } & Negative & $9(37.5 \%)$ \\
& Positive & $15(62.5 \%)$ \\
\hline
\end{tabular}

Table (2): Descriptive data of the detected lesions with increased FDG uptake ( $n=64)$.

\begin{tabular}{|l|l|c|}
\hline \multicolumn{2}{|c|}{ Lesions } & No.= 64 \\
\hline \multirow{2}{*}{ Breast/lymph nodes } & Breast & $36(56.3 \%)$ \\
& Lymph nodes & $28(43.8 \%)$ \\
\hline \multirow{3}{*}{ Type of carcinoma } & Invasive ductal & $59(92.2 \%)$ \\
& Invasive lobular(pleomorphic) & $4(6.3 \%)$ \\
& Mixed invasive ductal and lobular & $1(1.6 \%)$ \\
\hline \multirow{3}{*}{ Grade } & I & $14(22.2 \%)$ \\
& II & $38(60.3 \%)$ \\
& III & $11(17.5 \%)$ \\
\hline
\end{tabular}

64 malignant lesions were identified in 24 female patients. The majority of the lesions (36 malignant lesions (56.3\%)) were in the breast, whilst 28 malignant lesions (43.8\%) were in the draining lymph nodes. The most common histological type presented in the patients was invasive ductal and the most common grade was grade II as illustrated in Table (2).

Table (3): Size, SUV value of malignant lesions with increased FDG uptake in PET/CT (SUV ${ }_{\max }$ tumor) and SUV Value of malignant lesions/ Average SUV of the liver $\left(\mathrm{SUV}_{\max }\right.$ tumor/ $\mathrm{SUV}_{\text {average }}$ liver).

\begin{tabular}{|c|c|c|}
\hline \multicolumn{2}{|l|}{ Lesions in PET/CT } & No. $=64$ \\
\hline \multirow{6}{*}{ Size in $\mathbf{c m}^{2}$} & \multicolumn{2}{|l|}{ Breast } \\
\hline & Mean \pm SD & $2.835 \pm 1.131$ \\
\hline & Range & $1-5.20$ \\
\hline & Axilla & \\
\hline & Mean \pm SD & $1.90 \pm 0.81$ \\
\hline & Range & $0.80-4.20$ \\
\hline \multirow{2}{*}{ SUV $V_{\max }$ tumor } & Mean \pm SD & $5.79 \pm 2.90$ \\
\hline & Range & $0.92-15.93$ \\
\hline \multirow{2}{*}{ SUV $V_{\max }$ tumor/ SUV $V_{\text {average }}$ liver } & Mean \pm SD & $3.31 \pm 1.79$ \\
\hline & Range & $0.55-9.70$ \\
\hline
\end{tabular}

Table (4): Comparison between the $\mathrm{SUV}_{\max }$ tumor of the lesions with the histopathological type of the tumor.

\begin{tabular}{|c|c|c|c|c|c|}
\hline $\begin{array}{l}\text { SUV }_{\max } \\
\text { tumor }\end{array}$ & $\begin{array}{l}\text { Invasive } \\
\text { ductal }\end{array}$ & \begin{tabular}{|c|}
$\begin{array}{c}\text { Invasive } \\
\text { lobular } \\
\text { (pleomorphic) }\end{array}$ \\
\end{tabular} & $\mathbf{t}^{*}$ & $\begin{array}{c}\text { p- } \\
\text { value }\end{array}$ & Sig. \\
\hline Mean \pm SD & $8.84 \pm 1.64$ & $5.67 \pm 2.82$ & \multirow{2}{*}{$\begin{array}{c}3.57 \\
3\end{array}$} & \multirow{2}{*}{0.001} & \multirow{2}{*}{$\begin{array}{c}\text { HS } \\
*\end{array}$} \\
\hline Range & $7.3-11$ & $1.2-15.93$ & & & \\
\hline
\end{tabular}

Table (5): Comparison between the $\mathrm{SUV}_{\text {max }}$ tumor of the lesions with the histopathological grade of the tumor.

\begin{tabular}{|c|c|c|c|c|c|}
\hline & SUV $_{\max }$ tumor & \multirow{2}{*}{ Test value* } & \multirow{2}{*}{ P-value } & \multirow{2}{*}{ Sig. } \\
\hline & & Mean \pm SD & & & \\
\hline \multirow{3}{*}{ Grade } & $\mathrm{I}$ & $2.8 \pm 1.64$ & \multirow{3}{*}{4.938} & \multirow{3}{*}{0.010} & \multirow{3}{*}{$\mathrm{HS}^{* *}$} \\
\hline & II & $4.00 \pm 2.26$ & & & \\
\hline & III & $6.00 \pm 4.04$ & & & \\
\hline
\end{tabular}

*: One Way ANOVA

**HS: Highly significant

Table (6): Comparison between $\mathrm{SUV}_{\text {max }}$ tumor/ $\mathrm{SUV}_{\text {average }}$ liver with the histopathological grade of the tumor.

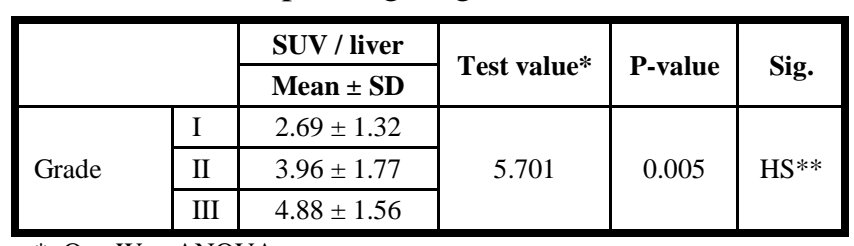

*: One Way ANOVA

**HS: Highly significant 
Table (7): Correlation of $\mathrm{SUV}_{\max }$ of the malignant breast lesions and their size.

\begin{tabular}{|l|c|c|}
\hline \multirow{2}{*}{} & \multicolumn{2}{|c|}{ SUV Value Breast } \\
\cline { 2 - 3 } & $\mathbf{r}$ & P-value \\
\hline Size in cm Breast & $0.428^{*}$ & 0.009 \\
\hline
\end{tabular}

*HS: Highly significant

Table (8): Correlation of $\mathrm{SUV}_{\max }$ of the pathological lymph nodes and their size.

\begin{tabular}{|l|c|c|}
\hline \multirow{2}{*}{} & \multicolumn{2}{|c|}{ SUV Value Axilla } \\
\cline { 2 - 3 } & $\mathbf{r}$ & P-value \\
\hline Size in cm Axilla & $0.470^{*}$ & 0.012 \\
\hline
\end{tabular}

*HS: Highly significant

Table (9): Correlation of $\mathrm{SUV}_{\max }$ tumor/ $\mathrm{SUV}_{\text {average }}$ liver and size of the breast lesions.

\begin{tabular}{|l|c|c|}
\hline \multirow{2}{*}{} & \multicolumn{2}{|c|}{ SUV Value / Liver Breast } \\
\cline { 2 - 3 } & $\mathbf{r}$ & P-value \\
\hline Size in cm Breast & $0.543^{*}$ & 0.001 \\
\hline
\end{tabular}

* HS: Highly significant

Table (9): Comparison between $\mathrm{SUV}_{\max }$ lymph node/ $\mathrm{SUV}_{\text {average }}$ liver and the size of lymph nodes.

\begin{tabular}{|l|c|c|}
\hline \multirow{2}{*}{} & \multicolumn{2}{|c|}{$\mathbf{S U V}_{\max }$ lymph node/ $\mathbf{S U V}_{\text {average }}$ liver } \\
\cline { 2 - 3 } & $\mathbf{r}$ & P-value \\
\hline Size in cm Axilla & $0.615^{*}$ & 0.000 \\
\hline
\end{tabular}

* HS: Highly significant

Table (10): Comparison between $\mathrm{SUV}_{\max }$ of lesions associated with presence distant metastasis and $\mathrm{SUV}_{\text {max }}$ of lesions that were not associated with distant metastasis.

\begin{tabular}{|l|l|c|c|c|c|c|}
\hline \multicolumn{2}{|c|}{} & $\begin{array}{c}\text { Negative } \\
\text { Metastasis }\end{array}$ & Positive & $\begin{array}{c}\text { Test } \\
\text { value* }\end{array}$ & $\begin{array}{c}\text { P- } \\
\text { value }\end{array}$ & Sig. \\
\hline \multirow{2}{*}{$\begin{array}{l}\text { SUV } \\
\text { Value }\end{array}$} & Mean \pm SD & $5.41 \pm 3.42$ & $6.00 \pm 2.59$ & -0.780 & 0.438 & NS** \\
\cline { 2 - 7 } & Range & $1.2-15.93$ & $0.92-11.2$ & & & \\
\hline
\end{tabular}

*: One Way ANOVA

** NS: Non significant

Table (11): Multivariable analysis of Logistic regression analysis for parameters that affect the level of SUV.

\begin{tabular}{|l|c|c|c|c|c|c|c|}
\hline & \multirow{2}{*}{ B } & S.E. & Wald & P-value & $\begin{array}{c}\text { Odds } \\
\text { ratio (OR) }\end{array}$ & \multicolumn{2}{|c|}{$\begin{array}{c}\text { 95\% C.I. } \\
\text { for OR }\end{array}$} \\
\cline { 6 - 8 } & & & Lower & Upper \\
\hline $\begin{array}{l}\text { Grade } \\
\text { (I/ II-III) }\end{array}$ & 2.318 & 0.727 & 10.157 & 0.001 & 10.154 & 2.441 & 42.237 \\
\hline $\begin{array}{l}\text { Size (<2.8 cm } \\
\text { I> 2.8) }\end{array}$ & 3.013 & 0.674 & 19.954 & 0.000 & 20.344 & 5.424 & 76.299 \\
\hline
\end{tabular}

\section{CASE PRESENTATION}

A 35 year old female patient, presented with right palpable breast mass. Biopsy was taken from the lesion and was proven to be infiltrating ductal carcinoma grade II. PET/ CT was done for initial staging prior to any surgical intervention.
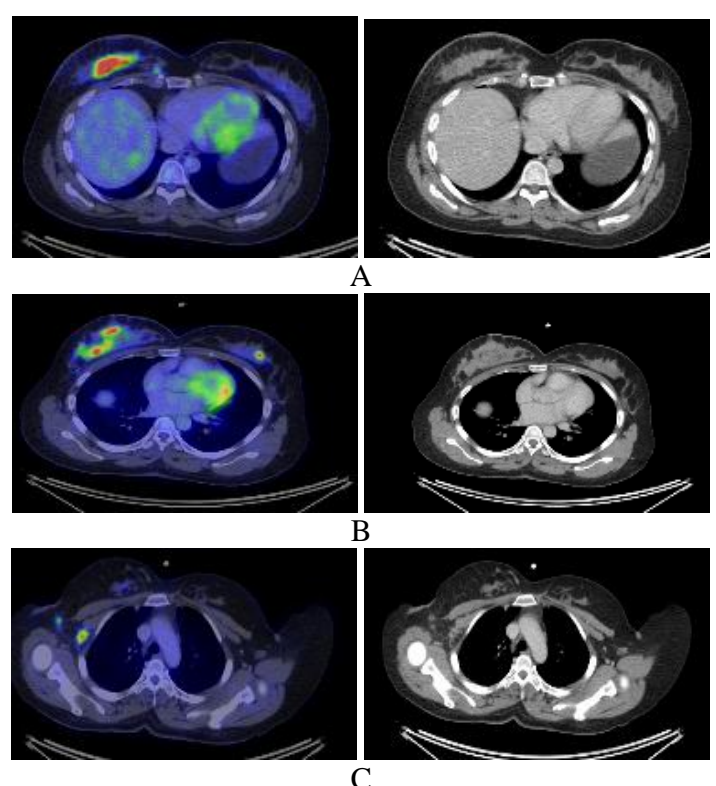

Figure (1): Axial fused PET/CT images with their corresponding CT images shows: Multiple variable sized metabolically active FDG avid right breast masses, the largest measures $5.2 \times 2.5 \times 2 \mathrm{~cm}$ with SUVmax 8.8. (Fig 1 a). A metabolically active FDG avid lesion is seen at the left breast seen measuring $11 \times 7.5 \mathrm{~mm}$ with SUVmax 5.9. (Fig 1 c). Multiple metabolically active FDG avid lymph nodes are seen involving both Axillary lymph nodes, largest on the right side measuring [2.3 x $1.4 \mathrm{~cm}$ with SUVmax $\sim 6.25$ (Fig 1 b) Liver activity $\sim 1.8$.
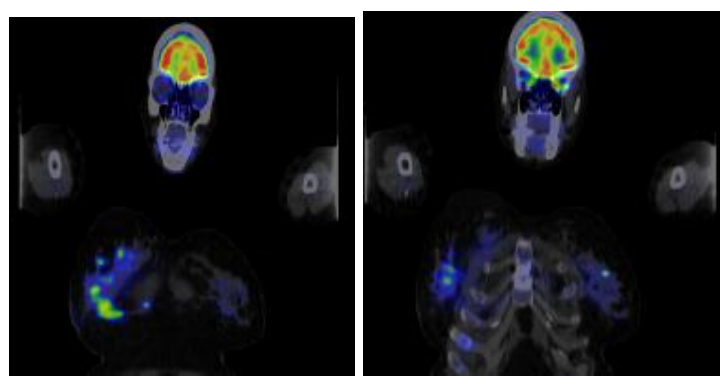

Fig (2): Coronal reformat of PET /CT fused images showing the multiple right breast lesions with avid FDG uptake.
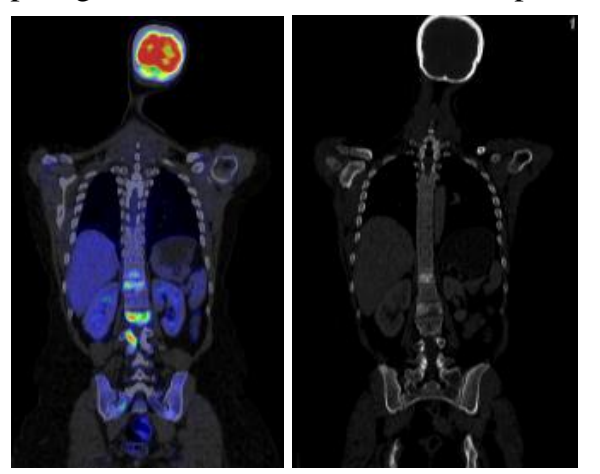

Fig (3): Coronal reformat of the PET CT fused images and corresponding CT images showing multiple osseous deposits T12 and L2 vertebral bodies Right ischium. 


\section{DISCUSSION}

FDG PET/CT is a noninvasive imaging modality that shows the metabolism of the tumor in addition to the anatomical details. Higher ${ }^{18} \mathrm{~F}$-FDG retention levels in malignant cells allow visualization of the tumor. $\mathrm{SUV}_{\max }$ is a semi quantitative method that indicates ${ }^{18} \mathrm{~F}$-FDG uptake, and the intensity of ${ }^{18} \mathrm{~F}$ FDG uptake is related to the increased proliferation activity in tumor cells and hence can estimate its behavior and prognosis.

In the literature, various studies have compared ${ }^{18} \mathrm{~F}$-FDG uptake with histopathological prognostic factors in patients with breast carcinoma. Brock et al. ${ }^{(8)}$ reported that tumors with high ${ }^{18} \mathrm{~F}-\mathrm{FDG}$ uptake levels were more aggressive than those with low ${ }^{18} \mathrm{~F}-\mathrm{FDG}$ uptake levels; therefore, ${ }^{18}$ F-FDG PET imaging could be informative as regards disease prognosis. Oshida et al.

(9) showed that disease-free survival rates were better in patients with lower $\mathrm{SUV}_{\max }$ than in those with higher $\mathrm{SUV}_{\text {max }}$ in breast carcinoma. In addition, Avril et al. ${ }^{(\mathbf{1 0})}$ found that ${ }^{18}$ F-FDG PET/CT is useful as a prognostic factor for breast carcinoma risk classification and for taking decisions on adjuvant chemotherapy ${ }^{(\mathbf{1 1})}$.

In this prospective study, we measured the tumor ${ }^{18}$ F-FDG uptake of 64 malignant lesions detected either in the breast or loco regional draining lymph nodes in 24 breast cancer female patients presented to Ain Shams University Hospitals (oncology, surgery and obstetrics /gynaecology departments) from June 2017 till June 2018.

The patients' age range in our study was from 29 to 69 years. Out of the 64 detected malignant lesions, the majority of the lesions (36 malignant lesions $(56.3 \%)$ ) were in the breast, whilst 28 malignant lesions $(43.8 \%)$ were in the draining loco regional lymph nodes. The most common histological type presented in the patients was invasive ductal carcinoma and the most common grade was grade II.

In the present study, FDG uptake is significantly higher in invasive ductal than invasive lobular breast carcinoma $(P<0.001)$. Several studies describing the relationship between ${ }^{18} \mathrm{~F}$-FDG uptake and histological tumor type have found that ${ }^{18} \mathrm{~F}-\mathrm{FDG}$ uptake values (SUV) are lower in invasive lobular carcinomas than in invasive ductal carcinomas ${ }^{(12)}$. This relationship can be explained by the lower density of tumor cells in lobular carcinomas, lower expression of GLUT1, lower proliferation rates and diffuse infiltrative tumor growing patterns to surrounding tissue ${ }^{(13)}$.
Avril et al. ${ }^{(\mathbf{1 0 )})}$ suggested that ${ }^{18} \mathrm{FFDG}$ uptake is lower in tumors with extended diffuse growing patterns, which mostly include invasive lobular carcinoma cases, than in tumors with nodular growth patterns. Thus $S U V_{\text {max }}$ of the tumor may play a role in identifying histological type of the tumor.

Tumor grade is a major predictive factor in breast carcinoma. During this study, a positive correlation is observed when correlating the $\mathrm{SUV}_{\max }$ tumor of the lesion with the histological grade. $(P$ $=0.010$, odds ratio $=10.154$ ). Thus higher grades of malignancy are possibly associated with higher $\mathrm{SUV}_{\max }$. This finding is in agreement with Ekmekcioglu et al. (11) $^{\text {(1) }}$ who carried out a study in 2013 on 136 women and four men with positive biopsy breast carcinomas who underwent ${ }^{18} \mathrm{~F}-\mathrm{FDG}$ PET/CT imaging for initial staging. He calculated Maximum standardized uptake values $\left(\mathrm{SUV}_{\max }\right)$ and tumor-to background $\mathrm{SUV}_{\text {max }}$ ratios and compared them with histopathological and immunohistochemical tumor characteristics, patient properties and axillary lymph node involvement. It concluded a positive correlation between $\mathrm{SUV}_{\text {max }}$ tumor of the lesion with the histological grade. $(\mathrm{P}=0.211)$. FDG-PET reflects the glucose metabolic activity in tumors and pathologic grade is used to describe the differentiation of tumor tissue reflecting the degree of malignancy. Since tumors with high glucose metabolism actively proliferate and tumors with high proliferation activity usually show high histological grade ${ }^{(\mathbf{1 0})}$. It is reasonable that high $\mathrm{SUV}_{\text {max }}$ is associated with high histological grade ${ }^{(14)}$. This may be due to high levels of Glut-1 encountered in the membrane of high grade tumor cells and increased level of hexokinase in their cytoplasm ${ }^{(15)}$. Other similar studies also corroborated these findings ${ }^{(16)}$.

The tumor size and the presence of necrosis are other factors that affect the $\mathrm{SUV}_{\text {max }}$ of a tumor. As tumor size increases, the likelihood of metastasis increases, and the overall survival rate decreases (17). Our study proved a positive correlation when correlating the $\mathrm{SUV}_{\max }$ tumor of the lesion whether in the breast or the lymph nodes with their size $(P=0.009$ in breast lesions and $P=$ 0.012 in lymph nodes, Odds ratio=20.344). Several studies have assessed the correlation between $\mathrm{SUV}_{\max }$ and tumor size. Some studies have reported a positive correlation between tumor size and ${ }^{18}$ F-FDG uptake ${ }^{(16)}$. This can be attributed to the fact that the increase in the tumor diameter was correlated with more glucose transporter-1 (Glut-1) expression on the surface of tumor cells and larger 
number of malignant cells with increased proliferation rate leading to increased FDG uptake ${ }^{(18)}$. However, Groheux et al. ${ }^{(12)}$ have found no relation. In Another study in 2001, Avril et al. ${ }^{(10)}$ found no association between ${ }^{18}$ F-FDG uptake and tumor size, and concluded that microscopic growth patterns of tumors could affect ${ }^{18} \mathrm{~F}$-FDG intensity and that diffuse infiltrating tumors such as invasive lobular carcinomas may be more affected by the partial volume effect. Therefore Groheux et al. ${ }^{(12)}$ excluded tumors smaller than $2 \mathrm{~cm}$ in size to reduce the partial volume effect. Similarly, considering the spatial resolution of PET/CT, a patient with a tumor measuring $5 \mathrm{~mm}$ or less was excluded from Ekmekcioglu et al. ${ }^{(11)}$. Another explanation to this negative relation is that tumor did not always have a uniform shape and a homogeneous composition, so tumor diameter could not represent the real tumor burden.

As expected, larger, aggressive and rapidly growing tumors show more necrosis due to tissue hypoxia. Contrary to the conventional wisdom that tumor necrosis dilutes standard uptake value; more necrosis was not associated with lower $\mathrm{SUV}_{\max }$. There was no correlation between $\mathrm{SUV}_{\max }$ and the degree of necrosis. This condition can be explained by the fact that $\mathrm{SUV}_{\text {max }}$ is calculated from the highest FDG uptake regions of the tumor ${ }^{(19)}$. On the contrary other studies reported high FDG uptake in presence of necrosis ${ }^{(11)}$. The reason behind this is that tissue hypoxia increases ${ }^{18} \mathrm{~F}$-FDG uptake in vitro as explained by Clavo et al. ${ }^{(20)}$.

Currently, ${ }^{18} \mathrm{~F}-\mathrm{FDG}$ PET/CT is playing an increasingly prominent role in breast cancer, with its high rate of accuracy, particularly in detecting nonaxillary lymphatic involvement and distant metastasis ${ }^{(21)}$. Basu et al. ${ }^{(22)}$ reported that ${ }^{18} \mathrm{~F}$-FDG uptake was higher in primary lesions of axillary and distant metastases than in those with only axillary involvement and no metastasis. Recently Arslan et al. ${ }^{(18)}$, found no relation was found between axillary involvement and $\mathrm{SUV}_{\max }$ values: yet, in cases where distant nodal uptake and distant metastasis were detected, statistically significantly high $S_{U V} V_{\max }$ values were obtained. These results were inconsistent with our study which showed no significant relationship between $\mathrm{SUV}_{\max }$ and presence of distant metastasis.

The standardized uptake value (SUV) currently is the nearly exclusive means for quantitative evaluation of clinical $\left[{ }^{18} \mathrm{~F}\right]$ fluorodeoxyglucose $\left({ }^{18} \mathrm{~F}-\mathrm{FDG}\right)$ positron emission tomography (PET) whole-body investigations. However, the SUV methodology has well-known shortcomings such as uptake time dependence of the SUV, unsatisfactory test/retest stability, susceptibility to errors in scanner calibration etc. (23) all of which adversely affect the reliability of the SUV as a surrogate of the metabolic rate of FDG (and ultimately of glucose consumption). In this context, it has been recognized repeatedly that at least part of the mentioned problems can be reduced or eliminated if tumor SUV is normalized to the SUV of a suitable reference region. Especially, the liver has drawn considerable attention as a useful reference region since the liver does not irreversibly trap the FDG and maintains a roughly constant SUV level during the time window relevant for whole-body FDG PET (about 60-120 min p.i.) ${ }^{(24)}$. Using the tumor-to-liver-ratio (TLR) obviously removes some of the SUV limitations, i.e. possible inaccuracies regarding actually injected dose, scanner calibration, and patient weight index (either actual body weight, lean body mass or body surface area) ${ }^{(25)}$.

During our study, we observed that when correlating the SUV max tumor/ $\mathrm{SUV}_{\text {average }}$ liver to the histological grade and size of the lesions, the significance of the positive correlation increased which high lightened and accentuated our results. To our knowledge, these histological prognostic parameters were not correlated with the $\mathrm{SUV}_{\text {max }}$ tumor/ $\mathrm{SUV}_{\text {average }}$ liver ratio in literature before. Several studies are thereby recommended to investigate this observation to improve accuracy of the results.

\section{CONCLUSION}

Breast cancer is the most common type of cancer and the second leading cause of cancer-related death among women. A new promising modality for the early yet accurate detection of relapsing cancer breast is the PET/CT scan. ${ }^{18} \mathrm{~F}$-FDG PET/CT provides fused images that demonstrate the complementary roles of functional and anatomic assessments in the diagnosis of cancer recurrence through the precise localization of suspected ${ }^{18}$ F-FDG foci and their characterization as malignant or benign. This study suggests that $\mathrm{SUV}_{\max }$ of the tumor is directly related to the histopathological grade and to the size of the tumor. Invasive ductal carcinoma has predominantly higher $\mathrm{SUV}_{\text {max }}$ than invasive lobular carcinomas. Also $\mathrm{SUV}_{\text {max }}$ tumor/ $\mathrm{SUV}_{\text {average }}$ liver is more accurate that $\mathrm{SUV}_{\text {max }}$ tumor alone. However, no relation between $\mathrm{SUV}_{\max }$ and the presence of distant metastasis. In conclusion, ${ }^{18} \mathrm{~F}-\mathrm{FDG}$ uptake may serve as a prognostic indicator for biological behavior in breast tumors. 


\section{REFERENCES}

1. Abdulrahman GO and Rahman GA (2012): Epidemiology of Breast Cancer in Europe and Africa. J Cancer Epidemiology. https:// www. hindawi. com/ journals/jce/2012/915610/

2. Ferlay J, Soerjomataram I, Dikshit R, Eser S, Mathers C, Rebelo M, Bray F (2015). Cancer incidence and mortality worldwide: sources, methods and major patterns in GLOBOCAN 2012. International journal of cancer, 136(5): 359-386.

3. Israel $O$ and Kuten A (2007): Early Detection of Cancer Recurrence: ${ }^{18}$ F-FDG PET/CT Can Make a Difference in Diagnosis and Patient Care. J Nucl Med., 48(1): 28-35.

4. Lind P, Igerc I, Beyer T et al. (2004): Advantages and limitations of FDG PET in the follow-up of breast cancer. European Journal of Nuclear Medicine and Molecular Imaging, 31(1): 125-134.

5. Czernin J (2002): FDG PET in breast cancer: a different view of its clinical use. Mol Imag Biol., 4:35-45.

6. Heinisch $M$, Gallowitsch $H$, Mikosch $P$, Kresnik E et al. (2003): Comparison of FDG PET and dynamic contrast enhanced MRI in the evaluation of suggestive breast lesions. Breast, 12:17-22.

7. Lim HS, Woong Y, Tae WC et al. (2007): FDG PET/CT for the Detection and Evaluation of Breast Diseases: Usefulness and Limitations. Radiographics, 27(1): 197-213.

8. Brock CS, Meikle SR, Price P (1997): Does fluorine $^{-18}$ fluorodeoxyglucose metabolic imaging of tumours benefit oncology. European Journal of Nuclear Medicine, 24:691-705.

9. Oshida M, Uno K, Suzuki M, Nagashima T, Hashimoto H, Yagata $H$ et al. (1998): Predicting the prognoses of breast carcinoma patients with positron emission tomography using 2-deoxy-2-fluoro $\left[{ }^{18}\right.$ F]-D-glucose. Cancer, 82: 2227-2234.

10. Avril N, Menzel M, Dose J, Schelling M, Weber W, Janicke F, Nathrath W, Schwaiger M (2001): Glucose metabolism of breast cancer assessed by ${ }^{18} \mathrm{~F}-\mathrm{FDG}$ PET: histologic and immunohistochemical tissue analysis. J Nucl Med., 42:9-16.
11. Ekmekcioglu O, Aliyev A, Yilmaz S, Arslan E, Kaya R, Kocaelb P, Engin Erkanc M, Halaca $M$ and Sonmezoglu $K$ (2013): Correlation of ${ }^{18} \mathrm{~F}$-fluorodeoxyglucose uptake with histopathological prognostic factors in breast carcinoma. Nuclear Medicine Communications, 34:1055-1067.

12. Groheux D, Giacchetti S, Moretti J-L, Porcher R, Espie' M, Lehmann-Che J et al. (2011): Correlation of high ${ }^{18} \mathrm{~F}-\mathrm{FDG}$ uptake to clinical, pathological and biological prognostic factors in breast cancer. Eur J Nucl Med Mol Imaging, 38:426-435.

13. De Cicco C, Gilardi L, Botteri E, Fracassi SL, Di Dia GA, Botta F et al. (2013): $\operatorname{Is}\left[\left({ }^{18}\right) \mathrm{F}\right]$ fluorodeoxyglucose uptake by the primary tumor a prognostic factor in breast cancer. Breast, 22:39-43.

14. Tomoo I, Kenji Y, Tetsuya T, Yasuhiro T, Eiichi S, Shinzaburo N (2004): Preoperative evaluation of prognosis in breast cancer patients by $\left[{ }^{18} \mathrm{~F}\right] 2$-Deoxy-2-fluoro-D-glucosepositron emission tomographyJournal of Cancer Research and Clinical Oncology, 130(5): 273-278.

15. Sanli Y, Kuyumcu S, Ozkan ZG, Işık G, Karanlik H, Guzelbey B, Mudun A (2012): Increased FDG uptake in breast cancer is associated with prognostic factors. Annals of nuclear medicine, 26(4): 345-350.

16. Gil-Rendo A, Martı'nez-Regueira F, Zornoza G, Garci'a-Velloso MJ, Beorlegui C, Rodriguez-Spiteri N (2009): Association between $\left[{ }^{18} \mathrm{~F}\right]$ fluorodeoxyglucose uptake and prognostic parameters in breast cancer. $\mathrm{Br} \mathrm{J}$ Surg., 96:166-170.

17. Razek AA, Gaballa G, Denewer A, Nada N (2010): Invasive ductal carcinoma: correlation of apparent diffusion coefficient value with pathological prognostic factors. NMR Biomed., 10:619-623.

18. Arslan E, Çermik TF, Trabulus FD, Talu EC, Başaran Ş (2018): Role of ${ }^{18} \mathrm{~F}$-FDG $\mathrm{PET} / \mathrm{CT}$ in evaluating molecular subtypes and clinicopathological features of primary breast cancer. Nuclear medicine communications, 39(7): 680-690. 
19. Koksal D, Demirag F, Bayiz H, Ozmen O, Tatci E, Berktas B, Yekeler E (2013): The correlation of $\mathrm{SUV}_{\max }$ with pathological characteristics of primary tumor and the value of Tumor/Lymph node $\mathrm{SUV}_{\max }$ ratio for predicting metastasis to lymph nodes in resected NSCLC patients. Journal of cardiothoracic surgery, 8(1): 63.

20. Clavo AC, Brown RS, Wahl RL (1995): Fluorodeoxyglucose uptake in human cancer cell lines is increased by hypoxia. J Nucl Med., 36:1625-1632.

21. Groheux D, Cochet A, Humbert O, Alberini JL, Hindié E, Mankoff D (2016): ${ }^{18}$ F-FDG $\mathrm{PET} / \mathrm{CT}$ for staging and restaging of breast cancer. J Nucl Med., 57:17-26.

22. Basu S, Mavi A, Cermik T, Houseni M, Alavi A (2008): Implications of standardized uptake value measurements of the primary lesions in proven cases of breast carcinoma with different degree of disease burden at diagnosis: does 2-deoxy-2-[F-18] fluoro-Dglucose-positron emission tomography predict tumor biology. Mol Imaging Biol., 10:62-66.
23. Weber WA, Gatsonis CA, Mozley PD, Hanna LG, Shields AF, Aberle DR, Govindan R, Torigan DA, Karp JS, Jian QY et al. (2015): Repeatability of 18F-FDG $\mathrm{PET} / \mathrm{CT}$ in advanced non-small cell lung cancer: prospective assessment in two multicenter trials. J Nucl Med., 114-147728.

24. Kunikowska J, Matyskiel R, Toutounchi S, Grabowska-Derlatka L, Koperski L, Królicki L (2014): What parameters from 18ffdg pet/ct are useful in evaluation of adrenal lesions. Eur J Nucl Med Mol Imaging, 41(12):2273-280.

25. Hofheinz F, Bütof R, Apostolova I, Zöphel K, Steffen IG, Amthauer H, van den Hoff J (2016): An investigation of the relation between tumor-to-liver ratio (TLR) and tumor-to-blood standard uptake ratio (SUR) in oncological FDG PET. EJNMMI Research., 6(1): 19. 